\title{
A Scoring System to Assess Patients with Diabetes: Nutech Functional Score
}

\author{
Geeta Shroff \\ Director and Founder, Nutech Mediworld, New Delhi, India \\ Email: geetashroff@hotmail.com
}

Received 3 September 2015; accepted 25 October 2015; published 28 October 2015

Copyright (C) 2015 by author and Scientific Research Publishing Inc.

This work is licensed under the Creative Commons Attribution International License (CC BY). http://creativecommons.org/licenses/by/4.0/

c) (i) Open Access

\begin{abstract}
Background: Diabetes mellitus (DM) is a metabolic disorder characterized by hyperglycemia. The symptoms of hyperglycemia include polyuria, polydypsia, polyphagia, blurred vision and weight loss. Various diagnostic tests are used for the diagnosis of DM in patients, but the findings of these tests cannot be assumed to be completely valid. This study aimed at developing a novel scoring system to assess the patients suffering from DM. Method: We assessed the patients based on various diagnostic tests available for DM and prepared a single list of these tests. The tests were categorized and graded based on the World Health Organization (WHO) criteria. Further, we coverted the grades into numeric values for easy use. Results: NFS for diabetes is an 11-point scoring system that assesses the patient's condition before and after therapy. To facilitate the conduct of probability based studies, we have converted the scores into numeric values in the range of $(0,1)$. Each symptom is graded as $(1,2,3,4,5)$ that runs in BAD $\rightarrow$ GOOD direction. Conclusion: NFS is a beneficial scoring system that can be used worldwide to assess the patients with DM.
\end{abstract}

\section{Keywords}

Diabetes Mellitus, Nutech Functional Score (NFS), Scoring System, Diagnosis

\section{Introduction}

Diabetes mellitus (DM) is a metabolic disorder characterized by hyperglycemia. It results from the defects in insulin secretion, insulin action or both. The symptoms of hyperglycemia include polyuria, polydypsia, polyphagia, blurred vision and weight loss [1]. Various pathological mechanisms are associated with the onset of DM. These include the destruction of beta $(\beta)$ cells in pancreas which causes insulin deficiency and abnormalities, resulting in blockage of insulin action [2].

DM can be classified into two broad types: Insulin Dependent Diabetes Mellitus or Type I (IDDS) and Non- 
Insulin Dependent Diabetes Mellitus or Type II (NIDDS) [3]. The cause for IDDS is an absolute deficiency of insulin secretion. NIDDS is caused by the combination of resistance to an insulin action and inadequate compensatory insulin secretory response [4].

Various diagnostic tests like random blood sugar, glycated hemoglobin $\left(\mathrm{HbA}_{1 \mathrm{C}}\right)$ and serological examination are used for the diagnosis of DM, before and after the treatment [5]. But, the findings of these tests cannot be assumed to be completely valid. For example, $\mathrm{HbA}_{1 \mathrm{C}}$ captures chronic hyperglycemia better than two assessments of fasting or 2-h oral glucose tolerance (OGT) test, but DM is clinically defined by high blood glucose and not by glycation of proteins [6]. Fasting plasma glucose (FPG) is a widely used automated diagnostic method, but it indicates only a single point blood glucose level. The findings of this test are known to be affected by the short term lifestyle changes, including stress and illness [7]. Diabetes is a chronic lifelong disease and a diabetic patient may have to continue medication throughout his life [8]. Further, if misdiagnosed, it can lead to several complications. Thus, diagnosing and assessing a patient with diabetes are crucial. The tests available for diagnosis of diabetes have one or other limitations and a physician cannot rely on a single or a couple of diagnostic tests [9]. A battery of diagnostic tests largely helps in assessing the patient. Further, it is also important to assess the patient accurately during the course of the therapy so that a better decision can be made for deciding the therapeutic strategy. Thus, it is crucial to assess the patient before and throughout the therapy.

To overcome the limitations associated with confirming the diagnosis of DM, we have introduced a novel numeric scoring system called the Nutech Functional Score (NFS), which can be used to evaluate/diagnose the patient before and after therapy. Currently, there is no scoring system for assessing the patients with DM. This paper discusses about the development of the NFS for the patients with DM.

\section{Materials and Methods}

\subsection{Material}

NFS comprises of a battery of tests that are deemed important to diagnose a patient with diabetes. Each of these tests or parameters is further sub-graded in to three to five categories. NFS evaluates each symptom in the list on the basis of five ordinal scores that run in BAD $\rightarrow$ GOOD direction. We have converted the scores into numeric values required for probability based studies in the range of $(0,1)$. All the patients evaluated with NFS were previously diagnosed with tests routinely used for the diagnosis of DM including blood sugar, serological examination and $\mathrm{HbA}_{1 \mathrm{C}}$.

\subsection{Method}

The study included both the pre-diagnosed diabetic patients and those who visited our facility and were diagnosed at the institute by routine diagnostic procedure. All the diagnostic tests that were used for evaluating the patients were recorded in the diagnostic history. The institute initiated assessing all the lists of recorded diagnostic tests and prepared a single list which included all the currently used diagnostic tests that are available to diagnose the diabetic patients.

\section{Results}

We have developed an 11-point scoring system to assess the patients with DM. This scoring system comprises of a battery of diagnostic tests that are essential to assess a diabetic patient. The five scores $(1,2,3,4,5)$ run in the direction $1 \rightarrow 5$ i.e. BAD $\rightarrow$ GOOD. These five numbers from $1 \rightarrow 5$ represent bad, not so bad, medium, not so good and good, respectively. These five scores are ordinal in the range of $(0.5,5.5)$. For probability based studies, we have converted these scores into the range of $(0,1)$. At any value of " $x$ ", where $Y_{c}=$ categorical score and $Y_{n}=$ numeric score, the relationship is supposed to be as $\frac{Y_{c}+0.5}{0.5}=x=\frac{Y_{n}+0.166}{0.096}$. Table 1 shows the conversion of five/three categorical scores $(0.5-5.5)$ for symptoms into five/ three numeric scores in the range $(0,1)$.

The NFS scoring details are presented in Appendix 1. NFS consists of tests that are routinely used to diagnose a patient with diabetes. The World Health Organization (WHO) criterion has been followed to grade a patient as diabetic. NFS comprises of $\mathrm{HbA}_{1 \mathrm{C}}$, FBS, post prandial blood sugar (PPBS), secondary complication, serum insulin levels, pre-dinner sugar levels, serum peptide, insulin levels, insulin with medication and medication 
Table 1. Conversion table from categorical scores to numeric range for NFS.

\begin{tabular}{ccccccc}
\hline \multirow{2}{*}{ End grade } & Score & \multicolumn{5}{c}{ Categorical grades } \\
\cline { 2 - 7 } & Range & $\mathbf{1}$ & $\mathbf{2}$ & $\mathbf{3}$ & $\mathbf{4}$ & $\mathbf{5}$ \\
\hline \multirow{2}{*}{5} & Score & 0.122 & 0.310 & 0.500 & 0.690 & 0.89 \\
& Range & $(0-0.241)$ & $(0.241-0.379)$ & $(0.379-0.621)$ & $(0.621-0.759)$ & $(0.759-1.00)$ \\
& Score & 0.167 & 0.500 & 0.833 & - & - \\
& Range & $(0-0.333)$ & $(0.333-0.667)$ & $(0.667-1.00)$ & - & - \\
\hline
\end{tabular}

level. All these tests are further sub-graded using the WHO criteria. For example, according to WHO, the cut-off point for diagnosing diabetes is $6.5 \mathrm{gm} \%$ for $\mathrm{HbA}_{1 \mathrm{C}}[10]$. In NFS, the $\mathrm{HbA}_{1 \mathrm{C}}$ is scored 1 : if $\mathrm{HbA}_{1 \mathrm{C}}$ is $>9.0 \mathrm{gm} \%$; 2: if $\mathrm{HbA}_{1 \mathrm{C}}$ is between 7.0 - 9.0 gm\%; 3: if $\mathrm{HbA}_{1 \mathrm{C}}$ ranges between $6.5-7.0 \mathrm{gm} \%$; 4: if $\mathrm{HbA}_{1 \mathrm{C}}$ falls between 6.0 - $6.5 \mathrm{gm} \%$; 5: if $\mathrm{HbA}_{1 \mathrm{C}}$ is $<6.0 \mathrm{gm} \%$. The WHO cut-off limit falls in the grade 4 of NFS. Similarly, all other diagnostic tests are sub-graded with respect to WHO [11] [12]. The conversion of these sub-grades in to numeric scores facilitates easy addition and substraction of grades making it easy to assess a patient after therapy for benefit, if any.

\section{Discussion}

$\mathrm{DM}$ is an endocrinology disorder resulting in improper functioning of pancreatic $\beta$ cells. The etiology of DM is multi-factorial and includes genetic factors coupled with environmental influences such as obesity associated with rising living standards, steady urban migration and lifestyle changes.

The diagnostic methods do not provide the complete evaluation of the patients with diabetes [13]. No single test seems to be useful in diagnosing diabetes. Further, there is variability in reporting of these tests which further leads to misdiagnosis. A review by Lippi and Targher established the limitations of $\mathrm{HbA}_{1 \mathrm{C}}$ test as it showed variation in diagnostic performance among different populations (i.e., pregnancy, elderly and non-Hispanic blacks), risk of over diagnosis in subjects with iron deficiency anemia, in subjects genetically predisposed to hyperglycation, and in those with increased red blood cell turnover [14]. Davidson and associates reported that the oral glucose tolerance test (OGTT) is poorly reproducible. The response to OGTT may be abnormal because of physical inactivity or carbohydrate intake [15]. Snehalatha et al. conducted a study on 1261 South Indian subjects having no known history of diabetes. Although, the results of this study showed high sensitivity (88.5\%) and specificity (85.2\%) for $\mathrm{HbA}_{1 \mathrm{C}}$ and sensitivity $(62.8 \%)$ and specificity $(61.2 \%)$ for $\mathrm{FPG}$ as per the WHO and American Diabetes Association (ADA) criteria, but 35\% variations were reported in $\mathrm{HbA}_{1 \mathrm{C}}$ that remain unexplained by FPG [16].

During the past years, studies comprising combination of diagnostic tests were carried out for accurate diagnosis of the patients with diabetes. But the combination of tests was also not able to completely explore the level of disease in patients. Mo et al. conducted a study on 6661 Chinese adults for diagnosis of type II diabetes by combining $\mathrm{HbA}_{1 \mathrm{C}}$ and FPG. They found that the threshold of $\mathrm{HbA}_{1 \mathrm{C}}$ and FPG were increased by combining the tests as compared to an individual test. Moreover, sensitivity and specificity of combining the use of $\mathrm{HbA}_{1 \mathrm{C}}$ and FPG were as high as $83.7 \%$ and $89.3 \%$, respectively; but false positive and negative results were also reported during the study [17].

On the basis of diagnosis, the patients are classified into three types viz. normal, borderline and diabetic. The normal type is defined as a group which would not progress to diabetes after follow-up of several years. The borderline type is defined as neither being normal nor of diabetic type [18] [19]. The current diagnostic methods clearly distinguishes the normal type and the diabetic type patients as there are clear cut-off limits set by WHO. However, it is usually difficult to diagnose a borderline patient using a single test or even after combining 2 - 3 tests. To mitigate these limitations, a novel numeric system called NFS has been introduced for evaluation of patients. In NFS, the various diagnostic tests have been scored in a direction $1 \rightarrow 5$ i.e. BAD $\rightarrow$ GOOD. These five numbers from $1 \rightarrow 5$ represents bad, not so bad, medium, not so good and good condition, respectively. The first two scores $(1,2)$ represents the diabetic type patients followed by the third and fourth score $(3,4)$ which represent the borderline type patients and the subsequent scores (5) represent the patients with good clinical status. Thus, the NFS scoring system can help physicians to even evaluate the patients that are at borderline. In the 
NFS system, the reference range of diagnostic tests is as per the WHO criteria. For example; the WHO cut off point for FPG is $126 \mathrm{mg} / \mathrm{dl}$ [11], this value corresponds to grade 4 in NFS i.e. $100-126 \mathrm{mg} / \mathrm{dl}$ (not so good condition). Similarly, other tests are also scored according to the WHO cut-off points [10] [12]. As per the NFS scoring, a patient is considered as improved if he scores 5 in all the diagnostic tests. The total score of all the tests should be 55 for a patient without diabetes. On the other hand, if the patient score falls in range of 54 to 33 , then he will be considered in borderline type and scores between 32 and 11 will be considered as diabetic type.

Let us take a hypothetical example to understand the use of NFS. Consider a diabetic male patient aged 32 years who is scored with NFS. Suppose,the patient is tested for fasting blood sugar (FBS). As per NFS, the FBS is scored 1: if FBS is $>300 \mathrm{mg} / \mathrm{dl}$; 2: if FBS is between $140-300 \mathrm{mg} / \mathrm{dl} ; 3$ : if FBS ranges between 126 and 140 $\mathrm{mg} / \mathrm{dl} ; 4$ : if FBS falls between 100 and $126 \mathrm{mg} / \mathrm{dl} ; 5$ : if FBS is $<100 \mathrm{mg} / \mathrm{dl}$ and if the patient does not have FBS then it is referred as NAA. Suppose the patient has been scored 2 for FBS before the treatment.

In the same way, PPBS also has 5 scores viz. 1: if PPBS is $>400 \mathrm{mg} / \mathrm{dl} ; 2$ : if PBBS is between 300 and 400 $\mathrm{mg} / \mathrm{dl}$; 3: if PBBS ranges between 200 and $300 \mathrm{mg} / \mathrm{dl}$; 4: if PBBS fall between 140 and $200 \mathrm{mg} / \mathrm{dl}$; 5: if PBBS < $140 \mathrm{mg} / \mathrm{dl}$ and NAA if it is not affected. Suppose the patient has a score 1 before treatment.

Secondary complication is also scored as; 1 : if multiple organs involved; 2: if $>4$ organs involved; 3: if 2 - 3 organs involved; 4: if 1 - 2 organs involved; 5: if no any organ involved and if patient does not have secondary complication then it is denoted as NAA. Let's assume that the patient is scored 2 for this symptom. Similarly, all other symptoms have been scored with NFS for this patient (Table 2). The total NFS score for patient is cumulative scores of all the symptoms.

As per NFS, the patient scored 18 and 37, before and after the treatment, respectively. The total score for symptoms increased as the patient moved from grades $1 \rightarrow 5$ in direction BAD $\rightarrow$ GOOD depicting an improvement (Table 2). The improvement shown by NFS also affects the course of therapy. As the patient moves from the lower scores to higher, representing an improvement, the level of medication also decreases. The other advantage of scoring system is that it also depicts even the slightest improvement/ deterioration in symptoms of the patient by addition and subtraction of the scores.

\section{Conclusion}

In conclusion, the diagnostic tests for DM possess several limitations that make it troublesome to assess the diabetic patients [13]. A unique numeric scoring system like NFS can be used to validate or confirm the diagnosis of DM in patients. However, we have only assessed and scored the patients with NFS at our center. We encourage the use of this system worldwide by other physicians and healthcare professionals. This will help to assess the reliability of NFS scoring system.

Table 2. Example of hypothetical scores of one patient before and after the treatment.

\begin{tabular}{|c|c|c|}
\hline Parameters & Scores before treatment & Scores after treatment \\
\hline $\mathrm{HbA}_{1 \mathrm{C}}$ & 2 & 4 \\
\hline FBS & 2 & 3 \\
\hline Post prandial blood sugar & 1 & 4 \\
\hline Secondary complication & 2 & 5 \\
\hline Serum insulin & 3 & 4 \\
\hline Post prandial blood insulin (60 min.) & NAA & NAA \\
\hline Pre-dinner & NAA & NAA \\
\hline Serum peptides & 2 & 4 \\
\hline Insulin level (treatment given) & 2 & 5 \\
\hline Insulin with medication & 3 & 4 \\
\hline Medication level & 1 & 4 \\
\hline Total score & 18 & 37 \\
\hline
\end{tabular}

$\mathrm{HbA}_{1 \mathrm{C}}$ : Glycated hemoglobin; FBS: Fasting Blood Sugar; NAA: Not affected. 


\section{Acknowledgements}

The author acknowledges all the doctors, staff and patients of the Nutech Mediworld. The author also acknowledges Knowledge Isotopes Pvt. Ltd. (http://www.knowledgeisotopes.com) for the writing support.

\section{Disclosure}

The author declares no conflict of interest.

\section{References}

[1] Tripathi, K.D. (2008) Essentials of Medical Pharmacology. Jaypee Brothers Medical Publishers (P) Ltd., New Delhi. http://dx.doi.org/10.5005/jp/books/10282

[2] American Diabetes, A. (2010) Diagnosis and Classification of Diabetes Mellitus. Diabetes Care, 33, S62-S69. http://dx.doi.org/10.2337/dc10-S062

[3] World Health Organization. Definition, Diagnosis and Classification of Diabetes Mellitus and Its Complications. http://whqlibdoc.who.int/hq/1999/who_ncd_ncs_99.2.pdf

[4] American Diabetes, A. (2004) Diagnosis and Classification of Diabetes Mellitus. Diabetes Care, 27, S5-S10. http://dx.doi.org/10.2337/diacare.27.2007.S5

[5] Herman, W.H. and Fajans, S.S. (2010) Hemoglobin A1c for the Diagnosis of Diabetes: Practical Considerations. Polskie Archiwum Medycyny Wewnetrznej, 120, 37-40.

[6] Bonora, E. and Tuomilehto, J. (2011) The Pros and Cons of Diagnosing Diabetes with A1c. Diabetes Care, 34, S184S190. http://dx.doi.org/10.2337/dc11-s216

[7] American Diabetes, A. (2011) Standards of Medical Care in Diabetes-2011. Diabetes Care, 34, S11-S61. http://dx.doi.org/10.2337/dc11-S011

[8] Garcia-Perez, L.E., Alvarez, M., Dilla, T., Gil-Guillen, V. and Orozco-Beltran, D. (2013) Adherence to Therapies in Patients with Type 2 Diabetes. Diabetes Therapy, 4, 175-194. http://dx.doi.org/10.1007/s13300-013-0034-y

[9] Venkataraman, K., Kannan, A.T. and Mohan, V. (2009) Challenges in Diabetes Management with Particular Reference to India. International Journal of Diabetes in Developing Countries, 29, 103-109. http://dx.doi.org/10.4103/0973-3930.54286

[10] (2011) Use of Glycated Haemoglobin (HbAlc) in the Diagnosis of Diabetes Mellitus. Abbreviated Report of a WHO Consultation. http://dx.doi.org/10.2337/diacare.27.2.335

[11] World Health Organization. Diabetes Programme. http://www.who.int/diabetes/action_online/basics/en/index1.html

[12] El-Kebbi, I.M., Ziemer, D.C., Cook, C.B., Gallina, D.L., Barnes, C.S. and Phillips, L.S. (2004) Utility of Casual Postprandial Glucose Levels in Type 2 Diabetes Management. Diabetes Care, 27, 335-339.

[13] National Institue of Diabetes and Digestive and Kidney Diseases. National Diabetes Information Clearinghouse. Comparing Tests for Diabetes and Prediabetes: A Quick Reference Guide. http:/www.niddk.nih.gov/health-information/health-topics/diagnostic-tests/comparing-tests-diabetes-prediabetes/Docu ments/Comparing_Tests_for_DM_508.pdf

[14] Lippi, G. and Targher, G. (2010) Glycated Hemoglobin (HbA1c): Old Dogmas, a New Perspective? Clinical Chemistry and Laboratory Medicine, 48, 609-614.

[15] Davidson, M.B., Peters, A.L. and Schriger, D.L. (1995) An Alternative Approach to the Diagnosis of Diabetes with a Review of the Literature. Diabetes Care, 18, 1065-1071. http://dx.doi.org/10.2337/diacare.18.7.1065

[16] Snehalatha, C., Ramachandran, A., Satyavani, K. and Vijay, V. (2000) Limitations of Glycosylated Haemoglobin as an Index of Glucose Intolerance. Diabetes Research and Clinical Practice, 47, 129-133. http://dx.doi.org/10.1016/S0168-8227(99)00109-6

[17] Mo, M., Zhong, W., Zhao, G., Ruan, Y., Zhang, H., Shi, L., et al. (2013) Combining Glycosylated Hemoglobin A1c and Fasting Plasma Glucose for Diagnosis of Type 2 Diabetes in Chinese Adults. BMC Endocrine Disorders, $13,44$. http://dx.doi.org/10.1186/1472-6823-13-44

[18] (1985) Diabetes Mellitus. Report of a WHO Study Group. World Health Organization Technical Report Series, 727 , $1-113$.

[19] Kuzuya, T., Nakagawa, S., Satoh, J., Kanazawa, Y., Iwamoto, Y., Kobayashi, M., et al. (2002) Report of the Committee on the Classification and Diagnostic Criteria of Diabetes Mellitus. Diabetes Research and Clinical Practice, 55, 6585. http://dx.doi.org/10.1016/S0168-8227(01)00365-5 
Appendix 1. Nutech functional score for patients with diabetes.

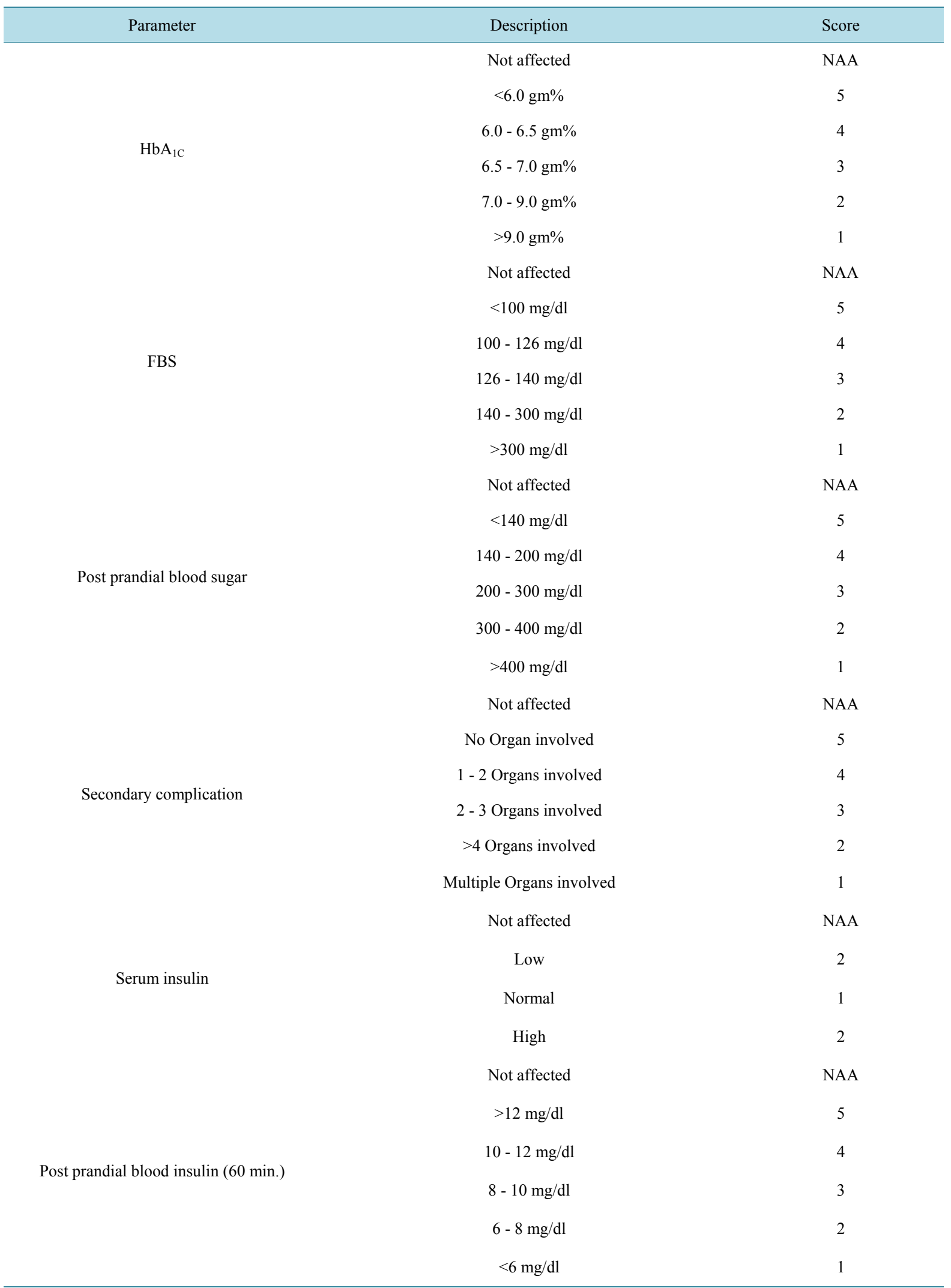




\section{Continued}

Pre-dinner blood sugar

Serum peptide

Insulin level (treatment given)

Insulin with medication (oral hypoglycemic)

Medication level (oral hypoglycemic)

\begin{tabular}{|c|c|}
\hline Not affected & NAA \\
\hline$<100 \mathrm{mg} / \mathrm{dl}$ & 5 \\
\hline $100-126 \mathrm{mg} / \mathrm{dl}$ & 4 \\
\hline $126-140 \mathrm{mg} / \mathrm{dl}$ & 3 \\
\hline $140-199 \mathrm{mg} / \mathrm{dl}$ & 2 \\
\hline$>200-400 \mathrm{mg} / \mathrm{dl}$ & 1 \\
\hline Not affected & NAA \\
\hline $0-0.5 \mathrm{mg} / \mathrm{ml}$ & 5 \\
\hline $0.5-1 \mathrm{mg} / \mathrm{ml}$ & 4 \\
\hline $1.5-2.0 \mathrm{mg} / \mathrm{ml}$ & 3 \\
\hline $2.0-2.5 \mathrm{mg} / \mathrm{ml}$ & 2 \\
\hline$>2.5 \mathrm{mg} / \mathrm{ml}$ & 1 \\
\hline Not affected & NAA \\
\hline $0-20 \mathrm{IU}$ & 5 \\
\hline $20-60 \mathrm{IU}$ & 4 \\
\hline $60-80 \mathrm{IU}$ & 3 \\
\hline $80-100 \mathrm{IU}$ & 2 \\
\hline$>100 \mathrm{IU}$ & 1 \\
\hline Not affected & NAA \\
\hline No Medication & 5 \\
\hline Insulin with 2 medications & 4 \\
\hline Insulin with 3 medications & 3 \\
\hline Insulin with 4 medications & 2 \\
\hline Insulin with more than 4 medications & 1 \\
\hline Not affected & NAA \\
\hline Not Taken & 5 \\
\hline $1-2$ & 4 \\
\hline $2-4$ & 3 \\
\hline $4-5$ & 2 \\
\hline$>5$ & 1 \\
\hline
\end{tabular}

$\mathrm{HbA}_{1 \mathrm{C}}$ : Glycated hemoglobin; FBS: Fasting Blood Sugar. 